\title{
POLIEMBRIONIA EM SEMENTES DE IPÊ-AMARELO: INFLUÊNCIA DE FATORES GENÉTICOS
} E AMBIENTAIS

\section{POLYEMBRYONY IN IPÊ-AMARELO SEEDS: INFLUENCE OF GENETIC AND ENVIRONMENTAL FACTORS}

\author{
Carlos Augusto Vargas; Laura Viana Vargas; Gladis Cleci Hermes Thomé
}

\section{RESUMO}

Apomixia é um tipo de reprodução com formação de sementes em que o embrião se origina por um processo assexual sem união de gametas. Há três tipos de mecanismos apomíticos sendo que um deles é a embrionia adventícia, e geralmente a embrionia adventícia está relacionada à ocorrência da poliembrionia, que é a formação de mais de um embrião por semente. O objetivo deste trabalho foram analisar: a influência do ambiente sobre as taxas de poliembrionia em sementes de ipê-amarelo, a existência de variabilidade para esta característica entre diferentes árvores matrizes e o efeito da poliembrionia sobre a morfologia das plântulas oriundas de sementes poliembriônicas. Foram coletados dez frutos de cinco árvores matrizes antes de sua maturação total, na qual foram separadas 400 sementes que foram colocadas para germinar em caixas gerbox e submetidas a $25^{\circ} \mathrm{C}$ com fotoperíodo contínuo, em câmara BOD. A análise dos resultados apontou diferença significativa para os caracteres analisados, apresentando no ano de 2014 uma porcentagem maior de germinação e no ano de 2016 uma porcentagem maior de poliembrionia. Foram encontrados de dois a seis embriões numa mesma semente, embora números maiores de embriões por semente (acima de quatro) não tenham sido observado em todas matrizes. Houve diferenças significativas entre as matrizes para todas as variáveis avaliadas podendo-se concluir que essas diferenças sejam devidas, principalmente, a efeitos genéticos e ambientais. Com base nas análises climáticas de temperatura e precipitação pode-se dizer que exerce influência sobre o comportamento fenológico, reprodutivo e vegetativo da espécie.

PALAVRAS-CHAVE: apomixia; embriões adventícios; Handroanthus chrysotrichus.

\section{ABSTRACT}

Apomixis is a type of reproduction with seed formation in which the embryo originates by an asexual process without union of gametes. There are three types of apomictic mechanisms being one of which is adventitious embryony, and usually is related to the occurrence of polyembryony, which is the formation of more than one embryo per seed. The objective of this work was to analyze the influence of the environment on the polyembryony rates in ipê-amarelo, the existence of variability for this characteristic among different mother trees, and the effect of polyembryony on the morphology of seedlings from polyembryonic seeds. Ten fruits were collected from five maturing trees before their total maturation, in which 400 seeds were separated and germinated in gerbox boxes and submitted to $25^{\circ} \mathrm{C}$ with continuous photoperiod in a BOD chamber. The analysis of the results indicated a significant difference for the characters analyzed, presenting in the year 2014 a higher percentage of germination and in the year 2016 a higher percentage of polyembryony. Two to six embryos were found in the same seed, although larger numbers of embryos per seed (above four) have not been observed in all mother trees. There were significant differences between the mother trees for all the variables evaluated and it can be concluded that these differences are mainly due to genetic and environmental effects. Based on the climatic analyzes of temperature and precipitation it can be said that it exerts influence on the phenological, reproductive and vegetative behavior of the species.
\end{abstract}

KEY WORDS: apomixis; adventitious embryos; Handroanthus chrysotrichus.

\section{INTRODUÇÃO}

A apomixia é um método geneticamente controlado de reprodução em plantas. É sinônimo de formação assexual da semente, que, no seu sentido mais amplo, significa "longe do ato da mistura" (CRUZ; FEDERIZZI; MILACH, 1998). Nesse tipo de reprodução, o embrião se desenvolve no ovário a partir de uma célula somática do óvulo, ocorrendo a formação de sementes férteis, sem haver a união do gameta feminino com o masculino, como ocorre na reprodução sexual.

Essa reprodução assexual é dividida em três tipos: diplosporia, aposporia e embrionia adventícia. Nos dois primeiros tipos de reprodução o saco embrionário forma-se sem a redução dos cromossomos, pois a meiose é substituída pela mitose, deixando o embrião com o mesmo número de cromossomos da mãe, classificando-os como apomixia gametofítica (GAUER; CAVALLI-MOLINA, 2000).

Quando o embrião adventício se forma diretamente no óvulo a partir de uma célula somática, sem a formação do saco embrionário, esse processo é chamado de apomixia esporofítica. Este processo inicia 
tardiamente no desenvolvimento do óvulo, geralmente ocorrendo em óvulos maduros (ASKER, 1979). Portanto, a reprodução sexual e a apomixia, podem acontecer no mesmo óvulo (KOLTUNOW; BICKNELL; CHAUDHURY, 1995).

Geralmente a embrionia adventícia está relacionada à ocorrência da poliembrionia, ou seja, formação de mais de um embrião por semente. Em algumas espécies, a formação do embrião sexuado é obrigatória, juntamente com a formação do endosperma, que serve de tecido nutritivo para os dois tipos de embrião (KOLTUNOW, 1993; MENDES-RODRIGUES, 2010).

A ocorrência desses processos está associada às características ambientais e à história de diferentes biomas. Muitos padrões ecológicos têm sido associados à apomixia, tais como distribuição geográfica mais ampla das espécies apomíticas em comparação com as espécies sexuadas relacionadas, associação com ambientes relativamente recentes e partenocarpia geográfica, formação de populações clonais, ocorrência de indivíduos monoembriônicos/sexuados e poliembriônicos/apomíticos, formando mosaicos reprodutivos numa mesma espécie (MENDES-RODRIGUES, 2010).

Diversos autores já relataram a ocorrência de poliembrionia em espécies como Citrus ssp. L. (GURGEL; SOUBIHE SOB ${ }^{\circ}$, 1951), Mangifera indica L. (CARVALHO; NAKAGAWA, 2000), espécies predominantes do Bioma Cerrado (MENDES-RODRIGUES, 2010) e espécies de ipê, como Handroanthus ochracea (tratada então como Tabebuia ochracea (Cham.) Standl.) (COSTA et al., 2004) e Handroanthus chrysotrichus (Mart. ex A. DC.) Mattos (MARCOLIN; NAGAOKA; PERES, 2013).

Costa et al. (2004) relatam em Handroanthus ochracea a ocorrência de até sete embriões por semente. Já Mendes-Rodrigues (2010) observou a formação de até sete embriões e até cinco plântulas por semente em um estudo conduzido com o Handroanthus chrysotrichus, porém nessa espécie a ocorrência de cinco ou quatro plântulas é considerada baixa, e quando ocorre diminui significativamente sua sobrevivência.

Handroanthus chrysotrichus, conhecida popularmente como ipê-amarelo, é uma espécie arbórea pertencente à família Bignoniaceae Juss. É nativa no Brasil, onde se distribui da Paraíba até Santa Catarina, sendo considerada como exótica no estado do Rio Grande do Sul (BACKES; IRGANG, 2003; FLORA DIGITAL, 2008). É uma planta decídua e heliófita, que possui dispersão descontínua e irregular. Floresce geralmente com a planta totalmente despida de folhagem e seus frutos deiscentes produzem grande quantidade de sementes, que amadurecem antes que o fruto se abra.

A madeira é moderadamente pesada, resistente, de grande durabilidade mesmo em condições adversas. É própria para obras externas e internas em construção civil. A árvore pode atingir até $10 \mathrm{~m}$ de altura e é extremamente ornamental, sendo muito utilizada para arborização em praças e ruas, devido ao seu pequeno porte (LORENZI, 1992). Essas características atribuem à espécie um alto valor econômico, o que justifica estudos que visem melhorar a produção e a qualidade de sementes e mudas (FONSECA et al., 2005).

A principal forma de propagação é através de sementes, levando até 14 dias para sua germinação (BACKES; IRGANG, 2004). Os frutos devem ser colhidos no início da abertura total, para garantia de um percentual alto de germinação (MARTINS; MARTINELLI-SENEME; NAKAGAWA, 2008).

Este trabalho teve como objetivos analisar a influência do ambiente sobre as taxas de poliembrionia em sementes de ipê-amarelo, a existência de variabilidade para essa característica entre diferentes árvores matrizes e o efeito da poliembrionia sobre a morfologia das plântulas oriundas de sementes poliembriônicas.

\section{MATERIAL E MÉTODO}

Foram coletados frutos de cinco árvores matrizes, selecionadas aleatoriamente e marcadas antes do período de floração. Essas matrizes apresentam distância mínima de $20 \mathrm{~m}$ entre si e estão localizadas no Campus I da Universidade de Passo Fundo (28 $13^{\prime} 41^{\prime}$ 'S 52 22'12'’O'), região norte do Rio Grande do Sul, no qual foram introduzidas.

Tendo em vista que a espécie produz frutos deiscentes, a coleta foi realizada no máximo duas semanas antes da maturação total dos frutos para evitar a dispersão das sementes. Foram coletados dez frutos de cada matriz, com tamanhos aproximadamente iguais e de ramos diferentes. Após a coleta, os frutos foram levados para o laboratório, colocados em bandejas, envoltos com jornal e expostos à luz solar indireta durante uma semana para secagem completa. De cada matriz foram separadas quatrocentas sementes. Além disso, foram misturadas oitenta sementes de cada uma das matrizes, constituindo um lote composto.

As sementes foram colocadas para germinar em caixas gerbox contendo dois papéis de germinação e 10 $\mathrm{mL}$ de água destilada. Foram feitas quatro repetições com cem sementes para cada árvore matriz e para o lote composto, conforme critérios estabelecidos nas Regras de Análise de Sementes - RAS (BRASIL, 2009). As caixas gerbox foram incubadas em câmara tipo B.O.D., sob iluminação constante e temperatura de $25^{\circ} \mathrm{C} \pm 1^{\circ} \mathrm{C}$, durante sete dias.

Esse experimento foi repetido em dois anos, 2014 e 2016, em que foram coletadas as sementes das mesmas 
árvores matrizes. No final de cada experimento foram determinados o percentual de germinação e a taxa de poliembrionia nas sementes.

Em 2016 foi avaliada a morfologia das plântulas oriundas de sementes poliembriônicas e realizada a análise do tamanho médio das plântulas, comparando o crescimento das plântulas oriundas de sementes poliembriônicas e monoembriônicas, com o auxílio de uma lupa. Essa análise foi realizada em plântulas de uma amostra de cinco sementes poliembriônicas de cada repetição. Sementes com número elevado de embriões (quatro ou mais) são de ocorrência mais rara; nesses casos a análise foi feita com um número menor de sementes, ou seja, com todas as plântulas das sementes poliembriônicas encontradas em cada repetição.

Durante o período reprodutivo, desde o início da floração até o amadurecimento dos frutos, foram observados e registrados os dados climatológicos como temperatura média e precipitação pluviométrica da região, obtidos do site da Estação Meteorológica da empresa Embrapa Trigo de Passo Fundo.

O delineamento experimental utilizado nos testes de germinação foi em blocos completamente casualizados. Os resultados obtidos foram submetidos à análise de variância e as médias separadas pelo teste de Tukey a $5 \%$ de probabilidade de erro.

\section{RESULTADOS E DISCUSSÃO}

O percentual de germinação apontou diferenças entre as árvores matrizes e entre os anos. No ano de 2014, destacam-se as que apresentaram maior percentual de germinação, com 95,5\% para a matriz 5 e 94,3\% para a árvore matriz 4. A matriz 1 apresentou o pior desempenho, com $38 \%$ de germinação seguido pela matriz 2 com $48,8 \%$ e pela matriz 3 com $61 \%$. Já no ano de 2016, o maior percentual de germinação foi obtido com a matriz 4 $(79,5 \%)$ seguido da matriz 5 , com $75,5 \%$. O baixo desempenho de germinação foi novamente observado nas matrizes 1,2 e $3, \operatorname{com} 23,5 \%, 30,3 \%$ e $15 \%$, respectivamente (Tabela 1 ).

A poliembrionia foi observada em todas as matrizes, sendo que a análise também apontou diferença significativa entre as matrizes em relação a essa característica. A matriz 5 foi a que teve a maior porcentagem de poliembrionia nos dois anos; apresentou 81,5\% de sementes poliembriônicas em 2014 e 85,5\%, em 2016. A menor porcentagem de sementes poliembriônicas foi observada na matriz 3 no ano de 2014, com 25,4\% e na matriz 1, com $34,1 \%$ no ano de 2016. Isso se deve, pois, além de ter altos níveis de incompatibilidade genética, nessa espécie ocorre fecundação cruzada e podem existir variações individuais entre as árvores devido às influências ambientais durante o desenvolvimento das sementes e à variabilidade genética.

TABELA 1: Percentuais médios de germinação e poliembrionia em sementes de cinco matrizes de Handroanthus chrysotrichus, em Passo Fundo, 2014 e 2016.

TABLE 1: Average percentage of germination and polyembryony in seeds of five Handroanthus chrysotrichus mother trees in Passo Fundo, 2014 and 2016.

\begin{tabular}{ccccccc}
\hline Árvore Matriz & \multicolumn{3}{c}{ Germinação (\%) } & \multicolumn{3}{c}{ Poliembrionia (\%) } \\
\cline { 2 - 6 } & 2014 & 2016 & CV\% & 2014 & 2016 & CV(\%) \\
\hline 1 & $38,0 \mathrm{~A} \mathrm{~d} *$ & $23,5 \mathrm{~A} \mathrm{bc}$ & 26,8 & $35,1 \mathrm{~A} \mathrm{c}$ & $34,8 \mathrm{~A} \mathrm{~b}$ & 10,7 \\
2 & $48,8 \mathrm{~A} \mathrm{c}$ & $30,3 \mathrm{~B} \mathrm{~b}$ & 8,3 & $29,7 \mathrm{~A} \mathrm{c}$ & $40,5 \mathrm{~A} \mathrm{~b}$ & 34,1 \\
3 & $61,0 \mathrm{~A} \mathrm{~b}$ & $15,0 \mathrm{~B} \mathrm{c}$ & 13,2 & $25,4 \mathrm{~A} \mathrm{c}$ & $40,6 \mathrm{~A} \mathrm{~b}$ & 24,7 \\
4 & $94,3 \mathrm{~A} \mathrm{a}$ & $79,5 \mathrm{~B} \mathrm{a}$ & 3,8 & $56,3 \mathrm{~B} \mathrm{~b}$ & $83,4 \mathrm{~A} \mathrm{a}$ & 11,8 \\
5 & $95,5 \mathrm{~A} \mathrm{a}$ & $75,5 \mathrm{~B} \mathrm{a}$ & 3,9 & $81,5 \mathrm{~A} \mathrm{a}$ & $85,5 \mathrm{~A} \mathrm{a}$ & 4,7 \\
\hline $\mathrm{CV}(\%)$ & 6,9 & 9,1 & \multicolumn{5}{c}{17,1} & 18,6 \\
\hline
\end{tabular}

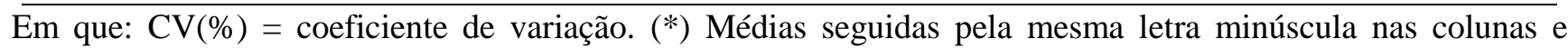
maiúscula nas linhas (dentro de germinação ou poliembrionia), não diferem significativamente de acordo com o Teste Tukey $(\alpha=0,05)$.

A existência de poliembrionia em sementes pode apresentar desvantagens aos embriões, visto que ocorre competição por espaço e nutrientes, podendo resultar em anomalias morfológicas, evitando que alguns dos embriões gerados se transformem em plântulas. Mas por outro lado, a poliembrionia pode acarretar em vantagem ecológica para a espécie, pois no caso de mais de um embrião estar bem nutrido, a capacidade de formar plântulas viáveis para a formação de mudas é maior, e mesmo quando uma das plântulas morre por competição, as demais tendem a se recuperar e podem alcançar um bom desenvolvimento (MENDES-RODRIGUES, 2010; MARCOLIN; NAGAOKA; PERES, 2013).

Não houve diferença significativa entre o percentual médio de germinação das cinco matrizes comparado à média do lote composto, tanto em 2014 quanto em 2016. O mesmo resultado foi obtido para o percentual de poliembrionia (Tabela 2), mostrando que independentemente do número de sementes utilizadas de cada matriz 
para formar o lote composto, a média geral das matrizes e do lote composto não terá uma diferença significativa.

Para Santos et al. (2009), a formação do lote composto é necessária para que haja representatividade no estudo de produção de mudas e plantios de recomposição ou de produção, proporcionando boa estimativa do comportamento médio da população estudada pela mistura equitativa de sementes das matrizes amostradas. E ao contrário do que afirmam os mesmos, os resultados sugerem que não é necessário trabalhar com número elevado de matrizes para formar o lote composto, pois a média das cinco matrizes analisadas não diferiu significativamente da média do lote composto.

TABELA 2: Comparação da média das cinco matrizes e do lote composto, em relação à porcentagem de germinação e de poliembrionia em sementes de Handroanthus chrysotrichus, em Passo Fundo, 2014 e 2016.

TABLE 2: Comparison of the average of the five mother trees and the composite batch, in relation to the percentage of germination and polyembryony in seeds of Handroanthus chrysotrichus, in Passo Fundo, 2014 and 2016.

\begin{tabular}{ccccc}
\hline & \multicolumn{2}{c}{ Germinação (\%) } & \multicolumn{2}{c}{ Poliembrionia (\%) } \\
\cline { 2 - 5 } & 2014 & 2016 & 2014 & 2016 \\
\hline Média das 5 matrizes & $67,5 \mathrm{~A}^{*}$ & $44,8 \mathrm{~A}$ & $45,6 \mathrm{~A}$ & $57,0 \mathrm{~A}$ \\
Lote composto & $73,5 \mathrm{~A}$ & $51,5 \mathrm{~A}$ & $51,7 \mathrm{~A}$ & $65,6 \mathrm{~A}$ \\
\hline CV\% & 7,5 & 11,5 & 8,9 & 13,6 \\
\hline
\end{tabular}

Em que: $\mathrm{CV} \%$ = coeficiente de variação. $\left.{ }^{*}\right)$ Médias seguidas pela mesma letra nas colunas não diferem significativamente de acordo com o Teste Tukey $(\alpha=0,05)$.

Conforme Santos et al. (2009), podem ocorrer diferenças entre as matrizes devido à influência do meio ambiente durante o desenvolvimento do fruto e a variabilidade genética.

Segundo os dados climatológicos obtidos da Estação Meteorológica da Embrapa Trigo (Tabela 3), a temperatura média durante o período reprodutivo do ipê amarelo foi $18,2^{\circ} \mathrm{C}$ em 2014 e $16,5^{\circ} \mathrm{C}$ em 2016 , e a precipitação média mensal foi de 176,9 mm em 2014 e 176,4 mm em 2016.

Nos meses de agosto e setembro, que foi o período de floração e desenvolvimento inicial dos frutos e sementes, tanto no ano de 2014 quanto no ano de 2016, não houve diferença em relação à temperatura. Porém, em relação à precipitação total, teve uma grande diferença entre os anos, pois pode ter afetando diretamente na germinação das sementes e consequentemente no resultado de poliembrionia, sendo uma explicação para os resultados obtidos, que comparado com o ano de 2014, em 2016 obteve-se uma porcentagem maior de sementes poliembriônicas. Isso se deve ao fato de que no período em que ocorreu o desenvolvimento das sementes, no ano de 2014 a precipitação foi menor, logo, a porcentagem de poliembrionia foi baixa, já que a planta não teve capacidade de produzir mais sementes por não ter tanta disponibilidade de água. No ano 2016 obteve-se uma alta taxa de poliembrionia nas sementes. Acredita-se, que, em consequência de as mesmas terem tido uma maior disponibilidade hídrica.

Essas mudanças climáticas e de temperatura podem influenciar e regular eventos fenológicos de acordo com sua intensidade e frequência e também influenciam a floração das árvores (FERRAZ et al., 1999; CÂMARA et al., 1997). Alguns estudos mostram que variáveis, como temperatura e precipitação, e as características nutricionais do solo, influenciam a fisiologia da planta e podem determinar padrões fenológicos (COSTA et al., 2007; PEREIRA-SILVA; JOLY; AIDAR, 2007; CARDOSO, 2009).

TABELA 3: Dados climatológicos de 2014 e 2016, obtidos da Estação Meteorológica da Empresa Embrapa Trigo Passo Fundo.

TABLE 3: Climatic data of 2014 and 2016 of the Meteorological Station of the company Embrapa Trigo Passo Fundo.

\begin{tabular}{ccccccccc}
\hline Ano & \multicolumn{3}{c}{2014} & \multicolumn{2}{c}{2016} \\
\hline \multicolumn{3}{c}{ Temperatura $\left({ }^{\circ} \mathrm{C}\right)$} & $\begin{array}{c}\text { Precip. } \\
\text { total }(\mathrm{mm})\end{array}$ & & Temperatura $\left({ }^{\circ} \mathrm{C}\right)$ & $\begin{array}{c}\text { Precip. } \\
\text { total }(\mathrm{mm})\end{array}$ \\
\hline Mês & Máx & mín & Média & & Máx & mín & Média \\
Ago & 21,5 & 9,9 & 14,7 & 126,1 & 19,5 & 10 & 14,1 & 187,7 \\
Set & 22,4 & 13,2 & 17 & 261,2 & 21,2 & 9,1 & 14,6 & 69,3 \\
Out & 26,4 & 14,8 & 19,8 & 176,8 & 23,9 & 12,4 & 17,5 & 370,2 \\
Nov & 27,7 & 16 & 21,2 & 143,6 & 27,2 & 13,9 & 19,9 & 78,5
\end{tabular}




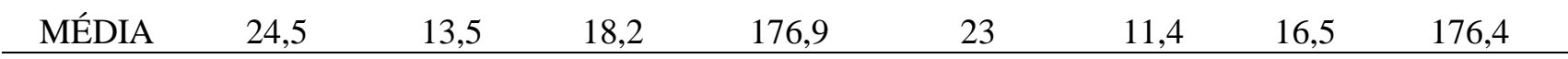

Conforme o número de embriões aumentava dentro da semente, o tamanho das plântulas obtidas a partir desses embriões reduziu, principalmente, se comparadas as sementes monoembriônicas às poliembriônicas com dois e três embriões (Figura 1). Nas sementes monoembriônicas notou-se que em todas as matrizes a média do tamanho das plântulas permaneceu alto, sendo a média mais baixa com $0,72 \mathrm{~cm}$ e a mais alta com $1,36 \mathrm{~cm}$.

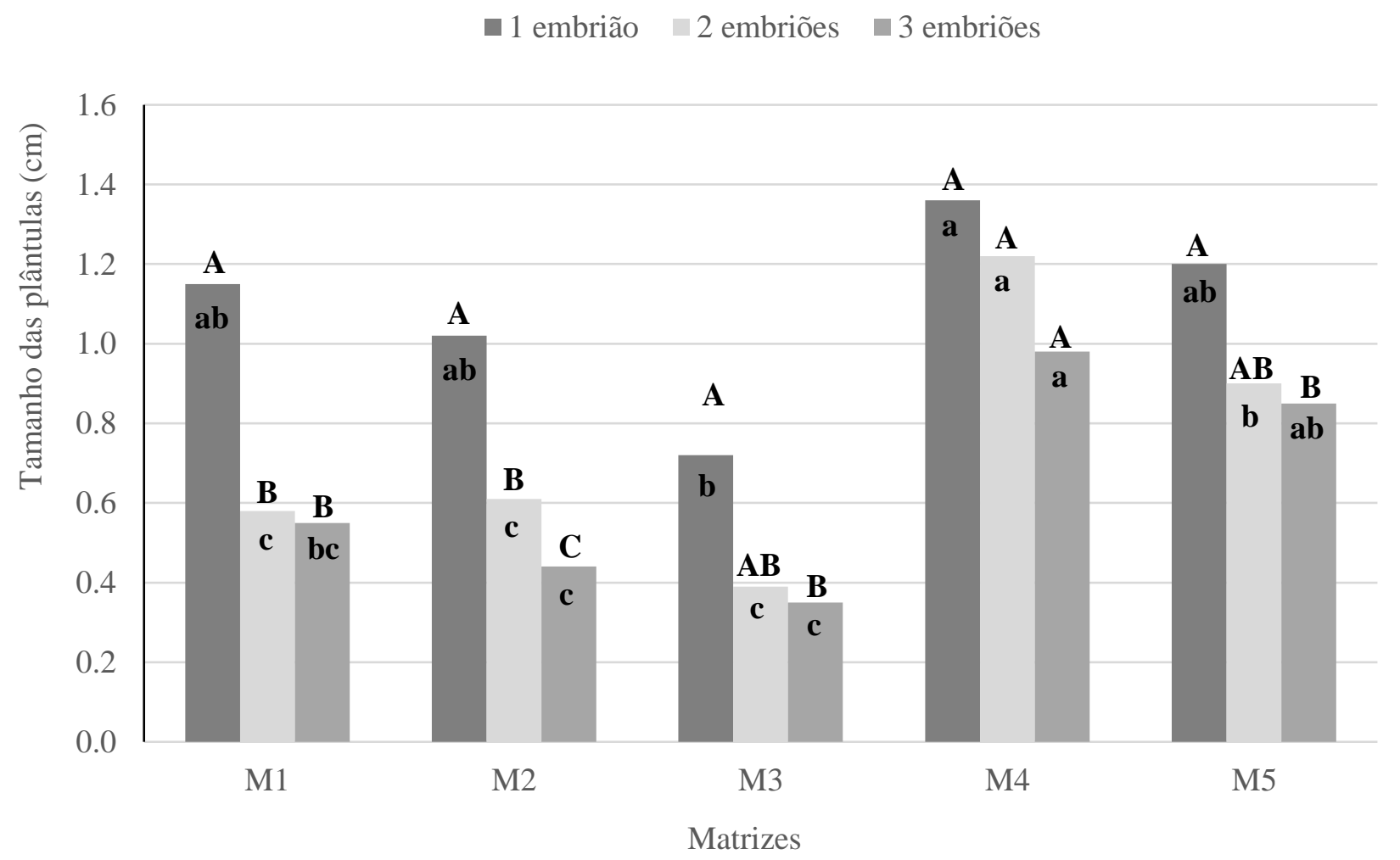

FIGURA 1: Tamanho médio das plântulas oriundas de sementes de cinco matrizes (M1 - M5) de Handroanthus chrysotrichus, contendo um, dois e três embriões, coletadas no ano de 2016. As plântulas foram medidas sete dias após o início do experimento. Letras iguais não diferem significativamente de acordo com o Teste Tukey $(\alpha=$ $0,05)$. Letras maiúsculas estão comparando o tamanho das plântulas dentro de cada matriz e as letras minúsculas estão comparando o tamanho das plântulas oriundas de sementes com um, dois ou três embriões, entre as cinco matrizes.

FIGURE 1: Average size of seedlings from seeds of five mother trees (M1- M5) of Handroanthus chrysotrichus, containing one, two and three embryos, collected in 2016. Seedlings were measured seven days after the start of the experiment. Equivalent letters do not differ significantly according to Tukey test $(\alpha=0,05)$. Capital letters are comparing the size of seedlings within each mother tree and the small letters are comparing the size of seedlings from seeds with one, two or three embryos among the five mother trees.

As matrizes 4 e 5 foram as únicas a apresentarem número máximo de até seis embriões, sendo que na matriz 4 foi encontrada uma única semente contendo sete embriões apresentando uma média de $0,3 \mathrm{~cm}$ no tamanho das plântulas obtidas. Conforme o número aumentou de cinco a seis embriões, dentro de uma mesma semente, o tamanho das plântulas diminuiu (Figura 2). 


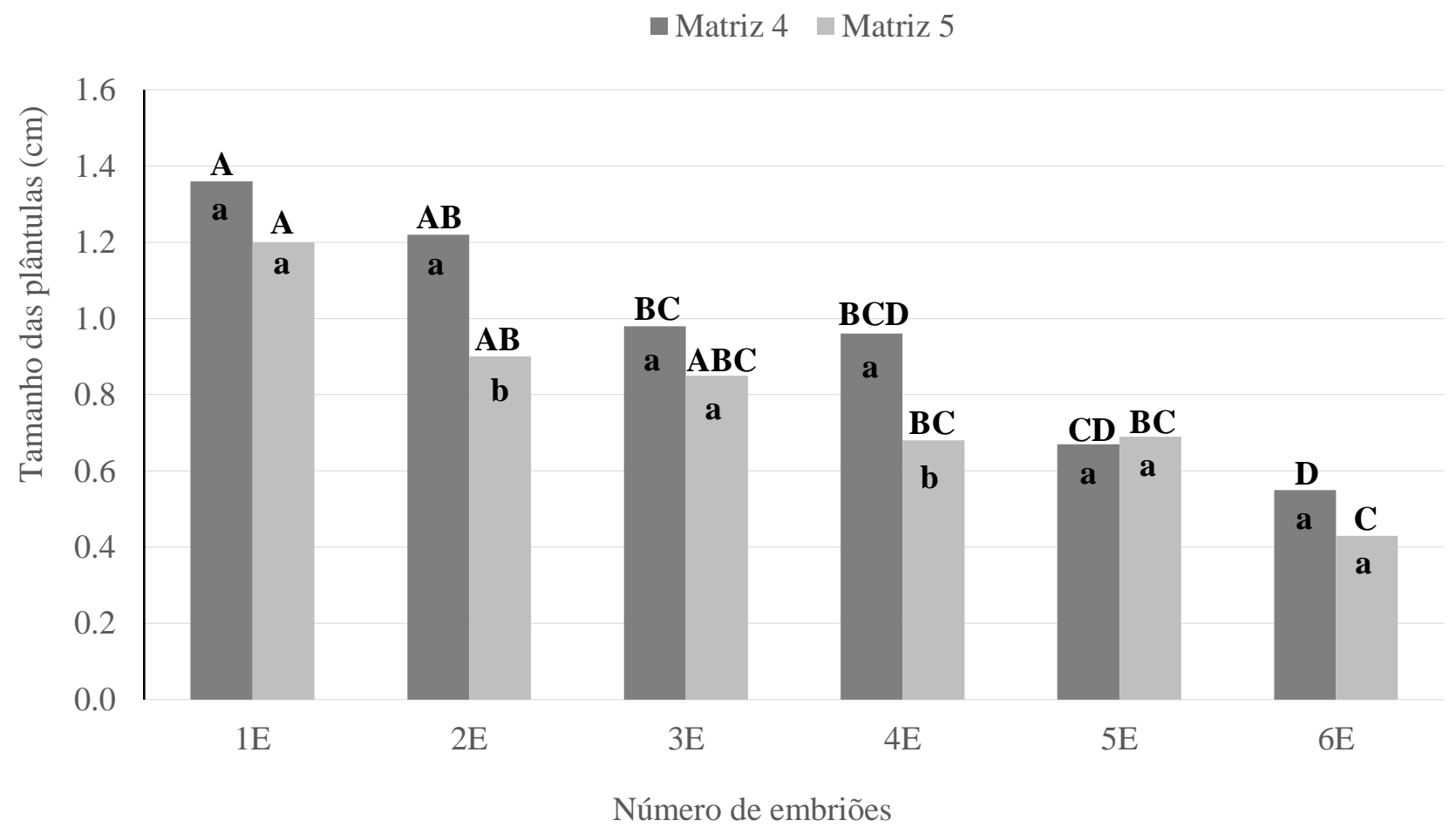

FIGURA 2: Tamanho médio das plântulas oriundas de sementes das matrizes 4 e 5 de Handroanthus chrysotrichus, contendo de um a seis embriões, coletadas no ano de 2016. As plântulas foram medidas sete dias após o início do experimento. Letras iguais não diferem significativamente de acordo com o Teste Tukey $(\alpha=$ 0,05). Letras maiúsculas estão comparando o tamanho das plântulas dentro de cada matriz e as letras minúsculas estão comparando o tamanho das plântulas oriundas de sementes de um a seis embriões, entre as duas matrizes. FIGURE 2: Mean size of the seedlings from the seeds of the 4 and 5 mother trees of Handroanthus chrysotrichus, containing from one to six embryos collected in the year of 2016. Seedlings were measured seven days after the start of the experiment. Equivalent letters do not differ significantly according to the Tukey test $(\alpha=0.05)$. Capital letters are comparing the size of seedlings within each mother tree and the small letters are comparing the size of seedlings from seeds of one to six embryos between the two mother trees.

As espécies que apresentam poliembrionia sofrem clonagem, pois somente um embrião será sexuado e os demais gerados serão clones da planta mãe, baixando seu nível de variabilidade genética. Estudos de variabilidade na ocorrência de poliembrionia devem levar em consideração as variações entre anos para um mesmo indivíduo, entre indivíduos de uma mesma população, entre populações de uma mesma espécie e entre espécies de um mesmo gênero ou família. Outros aspectos como nutrição, idade, condições ambientais também podem ter efeito sobre a expressão da poliembrionia, embora poucos estudos tenham se atentado aos fatores determinantes das variações na ocorrência de poliembrionia (ASKER; JERLING, 1992; NAUMOVA, 1992)

Uma hipótese para entender esse fenômeno que acontece é a compensação reprodutiva, a perda do embrião sexuado por má formação ou pela presença de genes letais devido à incompatibilidade dos gametas. Nesses casos a poliembrionia funciona como um processo seletivo de embriões mais aptos e vigorosos, atribuindo vantagens à espécie, aumentando o percentual para a formação de plântulas viáveis (MENDES-RODRIGUES, 2010).

\section{CONCLUSÃO}

Os resultados obtidos sugerem que efeitos genéticos e ambientais influenciaram diretamente a porcentagem de germinação e a taxa de poliembrionia de sementes de ipê-amarelo.

A poliembrionia afeta a morfologia das plântulas oriundas de sementes poliembriônicas. Conforme o número de embriões aumenta dentro de uma mesma semente, as plântulas apresentam, em média, menor tamanho quando comparadas às plântulas oriundas de sementes monoembriônicas.

Os resultados obtidos sugerem que a idade das plantas matrizes afeta a germinabilidade e a a taxa de poliembrionia das sementes. Sugere-se a realização de novos experimentos para comprovar essa hipótese. 


\section{REFERÊNCIAS}

ASKER, S. Progress in apomixis research. Hereditas, Lund, v. 91, p. 231-240, 1979.

ASKER, S. E.; JERLING, L. Apomixis in plants. CRC Press, Boca Raton, 1992. nativas sul-brasileira. São Paulo: UNISA, 325 p. 2004.

BRASIL. Regras de análise de sementes, Ministério da Agricultura, Pecuária e Abastecimento, 2009.

CÂMARA, G. M. S. et al. Influence of photoperiod and air temperature on the growth, flowering and maturation of soybean (Glycine max (L.) Merrill). Scientia Agricola, Piracicaba, v. 54, p. 149-154, 1997.

CARDOSO, F. C. G. Variações fenológicas de árvores da Floresta Atlântica, em diferentes condições de solo. Curitiba, 2009. 70 f. Dissertação (Mestrado em Ecologia e Conservação) - Universidade Federal do Paraná, Curitiba, 2009.

CARVALHO, N. M.; NAKAGAWA, J. A formação das sementes. In: CARVALHO, N. M.; NAKAGAWA, J. ed. Sementes: Ciência, tecnologia e produção. Jaboticabal: Funep, 4 ed., p. 12-53. 2000.

COSTA, M. E. et al. Poliembrionia e aspectos da embriogênese em Tabebuia ochracea (Chamisso) Standley (Bignoniaceae). Revista Brasileira de Botânica, São Paulo, v.27, n.2, p. 395-406, 2004.

COSTA, R. F. da et al. Transpiração em espécie de grande porte na Floresta Nacional de Caxiuanã, Pará. Revista Brasileira de Engenharia Agrícola e Ambiental, Campina Grande, v. 11, n. 2, p. 180-189, 2007.

CRUZ, R. P.; FEDERIZZI, L. C.; MILACH, S. C. K. A apomixia no melhoramento de plantas. Ciência Rural, Santa Maria, v. 28, n. 1, p.155-161, 1998.

FERRAZ, D. K. et al. Fenologia de árvores em fragmento de mata em São Paulo, SP. Revista Brasileira de Biologia., São Carlos, v. 59, n. 2, p. 305-317, 1999.

FLORA DIGITAL, Handroanthus chrysotrichus (Mart. Ex DC) Mattos, Disponível em: <http://www.ufrgs.br/fitoecologia/florars/open_sp.php?img=581>. Acesso em: 25 de fevereiro de 2018.

FONSECA, F. L. et al. Maturidade fisiológica das sementes do ipê amarelo, Tabebuia chrysotricha (Mart. Ex DC.) Standl. Scientia Forestalis, n. 69, p.136-141, dez. 2005.

GAUER, L.; CAVALLI-MOLINA, S. Apomixia: um método alternativo para a produção de sementes em plantas. Pesquisa Agropecuária Gaúcha, v. 6, n. 1, p. 157- 170, 2000.

GURGEL, J. T. A.; SOUBIHE SOB ${ }^{\circ}$, J. Análise de poliembrionia em Citrus, máxime em toranjas. Anais da Escola Superior de Agricultura Luiz de Queiroz, Piracicaba, v. 8, p. 727-746, 1951.

KOLTUNOW, A. M. Apomixis: embryo sacs and embryos formed without meiosis or fertilization in ovules. The Plant Cell, Baltimore, v. 5, p.1425- 1437, 1993.

KOLTUNOW, A. M.; BICKNELL, R. A.; CHAUDHURY, A. M. Apomixis: molecular strategies for the generation of genetically identical seeds without fertilization. Plant Physiol, Lancaster, v. 108, p.1345-1352, 1995.

LORENZI, H. Árvores brasileiras: manual de identificação e cultivo de plantas arbóreas nativas do Brasil. São Paulo: Instituto Plantarium, 382 p., 1992.

MARCOLIN, G.; NAGAOKA, R. E.; PERES, F. F. B. Germinação e poliembrionia em sementes de ipê-dourado armazenadas. Enciclopédia Biosfera, Centro Científico Conhecer - Goiânia, v. 9, n. 17, p. 1539, 2013.

MARTINS, C. C.; MARTINELLI-SENEME, A.; NAKAGAWA, J. Estágio de colheita e substrato para o teste de germinação de sementes de ipê (Tabebuia chrysotricha (Mart. ex DC.) Standl.). Revista Árvore, Viçosa, v. 32 , n. 1, p. 27-32, Feb. 2008.

MENDES-RODRIGUES, C. Ecologia de espécies poliembriônicas com ênfase no bioma cerrado. 2010.248 f. Tese (Doutorado em Ecologia e Conservação de Recursos Naturais) - Universidade Federal de Uberlândia, Uberlândia, 2010.

NAUMOVA, T. N. Apomixis in Angiosperms: Nucellar and integumentary embryony. CRC Press, Boca Raton, Florida, 1992.

PEREIRA-SILVA, E. F. L.; JOLY, C. A.; AIDAR, M. P. M. Relações entre precipitação, pulso de nitrogênio no solo e o transporte e uso do nitrato por espécies arbóreas de floresta ombrófila densa submontana, Parque Estadual de Carlos Botelho, SP. In: CONGRESSO DE ECOLOGIA DO BRASIL, 23 a 28 de set. 2007, Caxambu. Anais...Minas Gerais [s.n.], 2007. p. 01- 02.

SANTOS, F. S. dos et al. Biometria e qualidade fisiológica de sementes de diferentes matrizes de Tabebuia chrysotricha (Mart. Ex A. DC.) StandI. Scientia Forestalis, Piracicaba, v. 37, n. 82, p. 163-173, 2009. 